\title{
Delayed Tornadogenesis Within New York State Severe Storms
}

\author{
MATTHEW S. WUNSCH \\ NOAA/National Weather Service, Upton, NY, and School of Marine and Atmospheric Sciences, Stony Brook University, Stony Brook, NY \\ MICHAEL M. FRENCH \\ School of Marine and Atmospheric Sciences, Stony Brook University, Stony Brook, NY
}

(Manuscript received 11 June 2019; review completed 21 October 2019)

\begin{abstract}
Past observational research into tornadoes in the northeast United States (NEUS) has focused on integrated case studies of storm evolution or common supportive environmental conditions. A repeated theme in the former studies is the influence that the Hudson and Mohawk Valleys in New York State (NYS) may have on conditions supportive of tornado formation. Recent work regarding the latter has provided evidence that environments in these locations may indeed be more supportive of tornadoes than elsewhere in the NEUS. In this study, Weather Surveillance Radar-1988 Doppler data from 2008 to 2017 are used to investigate severe storm life cycles in NYS. Observed tornadic and non-tornadic severe cases were analyzed and compared to determine spatial and temporal differences in convective initiation (CI) points and severe event occurrence objectively within the storm paths. We find additional observational evidence supporting the hypothesis the Mohawk and Hudson Valley regions in NYS favor the occurrence of tornadogenesis: the substantially longer time it takes for storms that initiate in western NYS and Pennsylvania to become tornadic compared to storms that initiate in either central or eastern NYS. An analysis of approximate near-storm environments using the 13-km Rapid Refresh (RAP) is used to confirm that the long-lived storms encounter more tornado-favorable conditions leading up to tornadogenesis in the NYS valley regions.
\end{abstract}

\section{Introduction}

Although convection in New York State (NYS) is not as common as in other regions of the United States (e.g., the southern Great Plains, Midwest, and Southeast), resulting severe weather such as large hail, severe winds, and tornadoes can have significant societal impacts owing to large population densities (Fig. 1) in the region (e.g., Wurman et al. 2007; Colle et al. 2012). For instance, forecasters in NYS face several challenges in nowcasting tornadoes: highly variable terrain, marine influences from both the Atlantic Ocean and the Great Lakes, the presence of boundaries, and the prevalence of shallow and pulse-like convection. Also, a majority of NYS tornadoes occur within storms other than supercells (Lombardo and Colle 2011), which results in shorter warning lead times (LTs) as non-supercell tornadoes tend to be more difficult to detect (Colle et al. 2012; Kuster et al. 2012). Therefore, any improvements in the ability to establish localized regions that are favorable for severe weather events provide operational forecasters an opportunity for increased warning LT and skill.

Many aspects of tornadoes in the NEUS are different from those in the rest of the country. Tornadoes in the NEUS primarily occur from June through August, in the late afternoon or early evening (Johns and Dorr 1996; Brooks et al. 2003), although there is a secondary peak during the morning on Long Island and in New York City (Colle et al. 2012). In addition, there are subtle regional differences in seasonal peaks of tornadoes: July is the peak for most of the inland NEUS with an August peak for coastal locations (Colle et al. 2012). Lombardo and Colle (2011) found that NEUS tornadoes are most likely to be embedded within linear structures rather than supercell thunderstorms. In addition, perhaps the

Corresponding author address: Michael M. French, 111 Endeavour Hall, Stony Brook University, Stony Brook, NY, 11794 


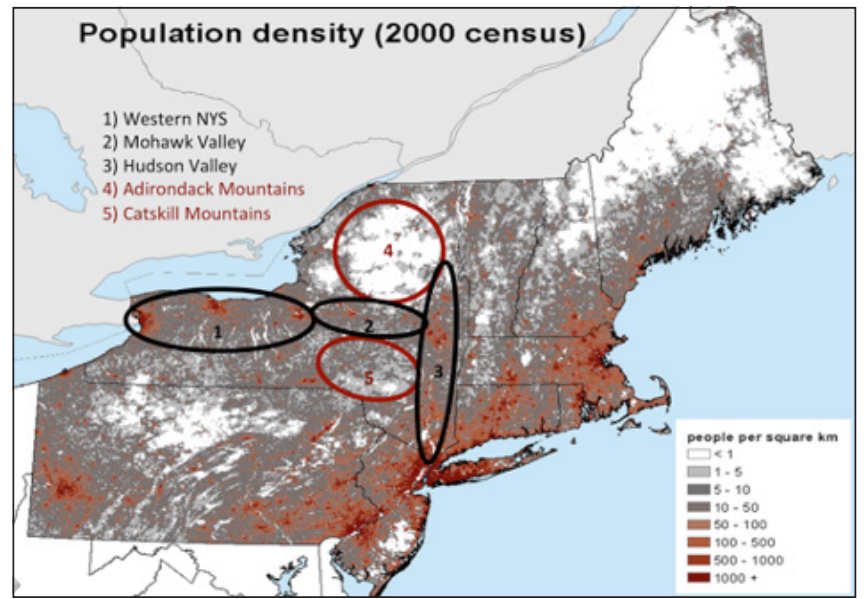

Figure 1. Population density of the NEUS using data from the 2000 census. Adapted from Hurlbut and Cohen (2014). Relevant geographical regions of interest are annotated for reference. Click image for an external version; this applies to all figures and hereafter.

most important regional difference from many other parts of the country is the influences on storm evolution introduced by the Atlantic Ocean and inland complex terrain.

Regarding the influence of the Atlantic Ocean, it has been shown there is a local minimum in all convection on Long Island and in coastal areas of New England (Murray and Colle 2011). However, it is unclear whether maritime air plays an important or lesser role compared to ambient synoptic-scale conditions in modulating organized convection like quasi-linear convective systems (Lombardo and Colle 2012, 2013), though a complex interplay between marine stable layer-cold pool collisions may be important (Lombardo and Kading 2018). Colle et al. (2012) examined tornadoes specifically in the New York City area and hypothesized when, and under what conditions, they form is influenced by the maritime air owing to observed environmental differences with tornadoes elsewhere in the NEUS. However, the small number of cases and poor observing capabilities over the Atlantic Ocean have thus far precluded more in-depth investigations of how the maritime air may affect tornado production in the NEUS.

Lack of observational data are less of a concern over inland NEUS areas, yet complex terrain is present. Regional terrain gradients have long been thought of as a potentially important contributor to tornado production throughout the United States (e.g., Fujita 1989; Knupp et al. 2014). In reference to the NEUS, Wasula et al. (2002) found a relationship between the $700 \mathrm{hPa}$ flow, terrain, and preferred locations of severe reports in parts of NYS and New England. More specifically, studies have found that channeled southerly flow in the NYS valley regions may play an important part in enhancing tornado production in those areas. The potential influence of the valleys on local storm environments originated with three case studies of local tornadic supercells. LaPenta et al. (2005) examined the 31 May 1998 Mechanicville, New York, tornado. The authors speculated that both instability and storm-relative helicity (SRH) were enhanced via a strong southerly jet channeled by way of the Hudson Valley. Similarly, a tornadic supercell case study was the subject of work by Bosart et al. (2006). In that case, the supercell mesocyclone strengthened and then the storm became tornadic as it crossed over the Hudson Valley coincident with channeled southerly flow that enhanced 0-1 km SRH. Finally, in Tang et al. (2016), the authors documented a strongly tornadic supercell that persisted despite a lack of favorable synopticscale conditions. The authors hypothesized that several mesoscale modifications of the environment induced by the terrain allowed the storm to flourish, including the presence of a baroclinic boundary along the Hudson Valley, that acted to increase vertical wind shear and moisture flux in the region.

Although analyzing significant severe convective events in the NEUS is important for storm-terrain interactions, only recently have NEUS severe storms been investigated from a climatological perspective. Lombardo and Colle $(2010,2011)$ analyzed composite reanalysis data associated with different types of convective morphologies in the NEUS, and Hurlbut and Cohen (2014) analyzed 10 years of proximity sounding data associated with severe and significant severe reports in the NEUS. However, the foci of these studies were on synoptic-scale environments of NEUS severe convection, while the use of coarse-resolution reanalysis and observed sounding data prevented a detailed examination of local mesoscale effects on severe weather production. Instead, Katona et al. (2016) analyzed storm environments over the NEUS from hundreds of convective events using the HighResolution Rapid-Refresh (HRRR) model. They found many subtle enhancements or reductions in variables known to be important for tornado formation in marine regions or those of varying terrain. For example, they found relative decreases in $0-1 \mathrm{~km} \mathrm{SRH}$ in western NYS, likely owing in part to a moderating effect from the marine air masses of Lake Erie and Lake Ontario 
(Fig. 2a, c, e). Coincident with reduced values of SRH were relatively low values of Convective Available Potential Energy (CAPE) in the vicinity of the Great Lakes and the Atlantic coast (Fig. 2b, d, f). More relevant to the three aforementioned case studies was an area of enhanced SRH they found located in central NYS coincident with, and likely caused by, the Mohawk Valley within southeast low-level flow regimes (Fig. 2e). In addition, the significant tornado parameter (STP; Thompson et al. 2003), a metric that combines instability, deep-layer shear, SRH, and cloud base height information to discriminate between nontornadic and strongly tornadic supercells, was enhanced in the NYS valley regions in southwesterly low-level flow days (not shown). The more favorable conditions borne out in a large amount of HRRR convective data are consistent with tornado formation that is locally favored in the NYS valley regions.

Ostensibly, the simplest way to identify regional tornado "hot spots" is to use observed clusters of tornadoes via reports and/or remote sensing data. Lombardo and Colle (2010) classified convective structures in the NEUS using composite radar data and Murray and Colle (2011) used radar and lightning data over seven warm seasons to identify where and when convective storms occur in the NEUS. In the latter study, the authors did find a local maximum in activity in the Mohawk and Hudson Valleys. However, the focus of both studies was on all types of convection, so that sample sizes were not a concern. Unfortunately, the relatively low number of tornadoes in the NEUS combined with the highly variable population density in NYS makes such an approach problematic (Fig. 1). Localized hot spots could arise from random chance, unavoidable population biases (e.g., Schaefer and Galway 1982), or a greater number of storms within low-level radar coverage. Ideally, methods to determine favored regional tornado locales leverages existing data while mitigating such biases.

The purpose of this study is to use one such approach to investigate the role the valley regions play on tornado formation: analyzing a large number of storm tracks using Weather Surveillance Radar-1988 Doppler (WSR-88D) data. In using storm life cycles, we rely more on radar data than storm reports to reduce population biases. And although the number of tornado events in these areas is relatively low, tracking tornadic and non-tornadic storms, and their characteristics, from initiation to dissipation might provide additional evidence of the role (or lack thereof) that terrain and

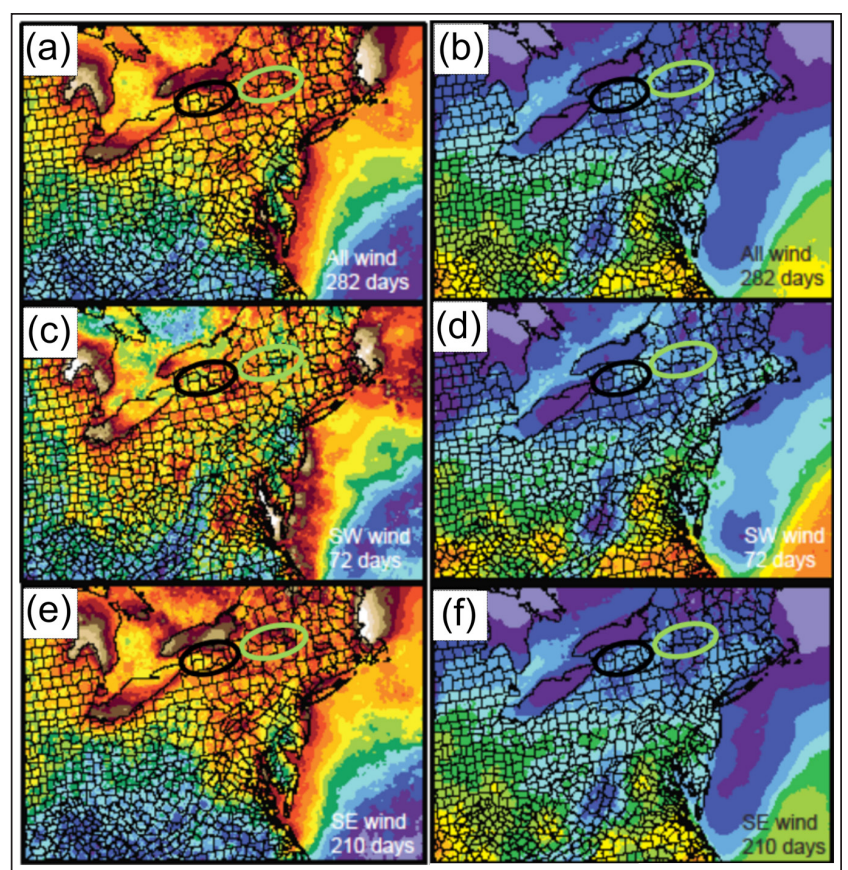

Figure 2. Mean $0-1 \mathrm{~km} \mathrm{SRH}\left(\mathrm{m}^{2} \mathrm{~s}^{-2}\right.$; left $)$ and mixedlayer CAPE ( $\mathrm{J} \mathrm{kg}^{-1}$; right) at $2100 \mathrm{UTC}$ on convective days between 1 February and 30 September 2013 through 2015 for (a, b) all days, (c, d) SW-flow days, $(e, f)$ SE-flow days in the NEUS. Adapted from Katona et al. (2016). Black oval denotes western NYS. Green oval denotes Mohawk Valley region of NYS.

marine influences play in storm evolution. The use of storm tracks also has precedent: Kovacs and Kirshbaum (2016) recently used a method that combines tracking storms via radar and using proximity environment data to investigate the influence of the complex topography on deep convection in the nearby region of southern Quebec.

In this paper, we detail an examination of a 10year database of manually tracked severe storms for evidence of modifications to storms as they traverse the variable terrain and marine influences of NYS. Section 2 discusses the data used and our methods for identifying the various stages of storm life cycles and severe events. In section 3, the results of an analysis of storm life cycles is discussed and the near-storm environmental changes the storms encounter are analyzed for a subset of storms. Summary and conclusions are in section 4 .

\section{Data and methods}

In order to analyze severe storm tracks, objective methods to identify the time and location of CI and severe weather initiation and cessation were used. 
All severe storm events were identified using both the Storm Prediction Center (SPC) and the National Centers for Environmental Information (NCEI) Storm Data archives. A convective event was included in this study if the cell of interest was associated with either a report of a tornado or hail $>2.5 \mathrm{~cm}$ (1 in) in diameter at any point in its lifetime ${ }^{1}$ within New England, NYS, Pennsylvania, and New Jersey, though the focus of this study is on NYS. WSR-88D Level II and III data were retrieved from the NCEI archive and analyzed using Solo-ii (Smith et al. 1995). In order to have a sufficient sample size of tornadic storm events in the NEUS, tornadic cases were analyzed from 2008 to 2017. The 10-year long analysis period mitigates but does not eliminate issues arising from the small number of storms that produce tornadoes in NYS $\left(\sim 8 \mathrm{yr}^{-1}\right)$. Also, the analysis of cases beginning in 2008 ensures all radar data that were used to track storm life cycles incorporated WSR-88D "Super Resolution" capabilities (Torres and Curtis 2007) that improve vortex detection. Hail-producing storms are more numerous than tornadic storms in NYS, so fewer years were analyzed in this study for hail storms (2015 to 2017), though a sufficient sample size was still obtained. Additionally, data for objectively identifying hail using the WSR88D network (see subsequent discussion) are limited farther back in time, as the hydrometeor classification algorithm (HCA) was updated for all NYS radar sites only within the last few years.

\section{a. Tornadic storms}

Using Storm Data reports in conjunction with SPC storm reports, tornadic events were identified from 2008 to 2017 in NYS. Once a tornadic event was identified, radar reflectivity factor $\left(\mathrm{Z}_{\mathrm{H}}\right)$ and radial velocity $\left(\mathrm{V}_{\mathrm{R}}\right)$ data were analyzed from the lowest elevation angle data at the scan time closest to the given estimated time and place of tornadogenesis in the report. For this study, the time and location of tornadogenesis was determined by using the report as a first guess and then objectively refining report information using $\mathrm{V}_{\mathrm{R}}$ data. Tornado reports often do not include the correct time and location

\footnotetext{
${ }^{1}$ Storms associated only with severe wind reports were excluded in this study, as their identification cannot be consistently validated by remote sensing techniques and therefore population-related biases cannot be mitigated. In addition, severe wind is the most common type of severe weather in the NEUS by far, so any large spatial gaps in reports would likely be heavily biased by population density.
}

of the event (e.g., Witt et al. 1998; French et al. 2009), so the use of WSR-88D data provides more confidence that the time and location of the tornado life cycle are accurate. To identify a tornado, we used a $\Delta \mathrm{V}$ (sum of maximum inbound and outbound $\mathrm{V}_{\mathrm{R}}$ magnitudes) threshold of $20 \mathrm{~m} \mathrm{~s}^{-1}$ within the tornadic vortex signature (TVS; Brown et al. 1978). The time and location of each successive radar scan that included a TVS with $\Delta \mathrm{V}>20 \mathrm{~m} \mathrm{~s}^{-1}$ within a $2 \mathrm{~km}$ diameter was recorded until tornado dissipation occurred. It is important to note that TVSs become more difficult to identify at long ranges as the lowest beam level is observing a higher altitude in the storm and the radar beam broadens. As a result, TVSs in radar "holes" are difficult to track and so we more heavily base the tornadic start/end time on the reports. Likewise, tornado dissipation was determined by analyzing the time and location of the final scan of the TVS in conjunction with reported dissipation. The relatively weak $\Delta \mathrm{V}$ threshold of $20 \mathrm{~m} \mathrm{~s}^{-1}$ (e.g., Trapp et al. 1999) was used to ensure more accurate begin/end times and locations of tornadoes in NYS, which tend to be weak and short lived compared to those in other regions in the United States We found the use of this threshold minimized differences from the approximate tornado time and location via Storm Data.

After identifying the radar scan associated with tornadogenesis, the storm was then tracked backwards in time to when the cell associated with the tornado was initially identified on radar. The time and location of the first scan with $Z_{H}>35 \mathrm{dBZ}$ using any beam angle was considered the initiation point of the cell $(\mathrm{CI})^{2}$. The use of a threshold of $Z_{\mathrm{H}}>35 \mathrm{dBZ}$ to indicate $\mathrm{CI}$ is typical in many studies that tracked movements of storms, and also has been used as a cutoff for the difference between a weakly precipitating storm and a vigorous convective storm (Roberts and Rutledge 2003). Once CI was identified, the cell was then tracked forward in time from the final scan where there was a TVS with $\Delta \mathrm{V}>20 \mathrm{~m} \mathrm{~s}^{-1}$ until the cell exhibited $\mathrm{Z}_{\mathrm{H}}<35 \mathrm{dBZ}$ at all levels. The last reflectivity echo of $Z_{H}>35 \mathrm{dBZ}$ for the associated cell was considered the time and location of the cell's dissipation. An example of the methods used for a tornadic supercell case is shown in Fig. 3: CI (Fig. 3a), first and last TVS scans (Fig. 3b, c, respectively), and storm dissipation (Fig. 3d).

\footnotetext{
2 The initiation times and locations of squall lines with embedded tornadoes were estimated by using the initiation time of the squall line itself with the same $Z_{\mathrm{H}}>35 \mathrm{dBZ}$ threshold.
} 


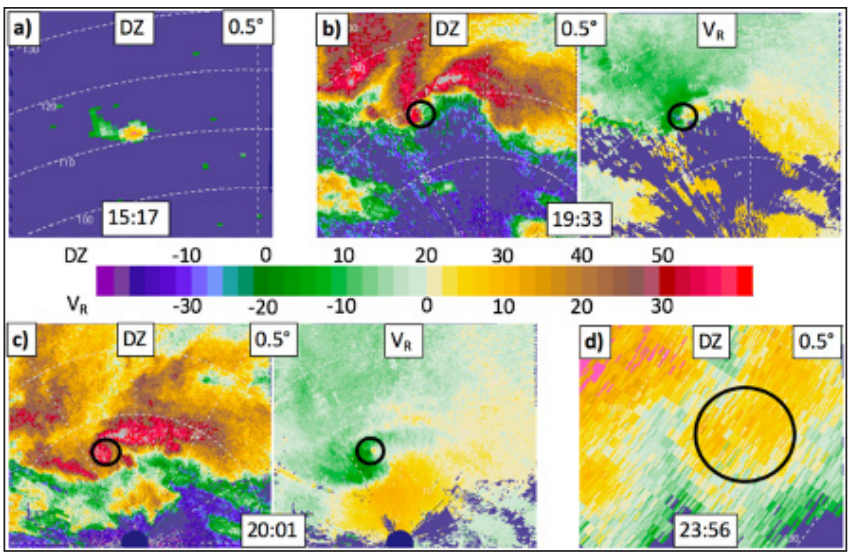

Figure 3. WSR-88D reflectivity factor (dBZ) and radial velocity $\left(\mathrm{m} \mathrm{s}^{-1}\right)$ depicting how the time and location of: (a) CI; (b) tornadogenesis; (c) tornado dissipation; and (d) cell dissipation were identified for a tornadoproducing supercell in east-central NY on 24 May 2014 from the KENX site. Black circles enclose the hook echo in (b), TVS in (c), and cell remnants in (d).

\section{b. Non-tornadic storms}

Similar methods to those described in section 2a were performed for the severe non-tornadic cells, but with additional steps to identify when hail was occurring. To provide a comparison between those storms that produced a tornado and those that did not, storms that were tornadic and also produced severe hail were not included in the non-tornadic (severe hail) dataset. As with the tornadic cases, the radar analysis began at the point of the first severe report of hail. If the WSR-88D HCA (Park et al. 2009) identified hail in the storm in the lowest elevation angle at the time nearest to the report, the cell was tracked backwards until the first scan where the HCA identified hail was reached; the corresponding time was considered the start time of the severe hail. If, at the initial report of severe hail, the HCA did not identify hail, the time of the first report was considered the start time of the severe hail. The cell then was tracked backwards in time in an identical fashion to the tornadic cases in order to identify the time of storm CI. The life span of severe hail was estimated using the HCA, and so the cell was tracked forward in time until the HCA ceased identifying hail. The last scan where the HCA identified hail was considered the severe hail end time.

As with TVSs, the HCA becomes less accurate in determining what is occurring at the surface as storms are observed further from radar sites owing to poor lowlevel sampling. The HCA subsequently becomes more accurate in identifying true surface hydrometeor type as storms approach a radar site. The use of the HCA as the sole tool used in determining the presence of hail at non-report times introduces inevitable uncertainty, though the focus in this study is using hail as a proxy for "non-tornadic severe storms" and thus the use of an initial hail report mitigates such concerns.

\section{c. Near-storm environments}

An additional component of this study is analysis of the near-storm environments (NSEs) that storms encountered during their life cycles in order to draw inferences about the potential impacts on NSEs by the surrounding terrain (hypothesized increase of SRH in the vicinity of the Mohawk Valley) and marine presence (hypothesized to stabilize nearby environments). Life cycle characteristics (i.e., CI, severe transition by way of severe hail or a tornado occurrence, and dissipation) of all cases were viewed spatially to determine if there were any clear geographical differences of any characteristics between tornadic and non-tornadic cases. This part of the study parallels the storm environmental study done by Katona et al. (2016).

The RAP analysis, using 13-km grid spacing, was used to identify environmental characteristics of interest near the location of CI and severe transition in individual cases. Storm environments analyzed from cases before 1 May 2012 used the RUC because the RAP was not operational. An unavoidable shortcoming of using RAP/RUC data is they may not accurately represent environmental influences of complex topography owing to the $13-\mathrm{km}$ grid spacing of the model. The environmental variables analyzed at these times and locations were surface-based (SB) CAPE, 0-1 km SRH, dewpoint depression (DD), and relative humidity (RH).

The parameters chosen are all known to be important in the development of severe convection and tornadoes. SBCAPE was analyzed to quantify surfacebased instability available for storms (convection should be surface-based to produce a tornado). $0-1 \mathrm{~km}$ $\mathrm{SRH}$ was investigated for its relationship to low-level rotation potential in convective storms. DD and RH at the surface are used as a proxy for lifting condensation levels (LCLs), in that low DDs and high surface RHs are tied to low LCLs. In turn, LCLs have been shown to be a skillful discriminator between tornadic (lower LCLs) and non-tornadic (higher LCLs) storms (Rasmussen and Blanchard 1998). In addition, local storm environments 
for tornadic events were separated into different lowlevel flow regimes based on environmental differences identified by Katona et al. (2016).

The NSE of each storm was evaluated by identifying the RAP or RUC gridpoint in the warm sector just downstream (based on storm motion) of the storm. The gridpoint chosen to identify the ambient NSE at each time and location is the nearest point downstream of the cell that is outside of any precipitation in the model (and observations) as to not be convectively contaminated. This approach ensured that the conditions of the environmental air being ingested by the storm were estimated. The gridpoint process was repeated from CI to tornadogenesis for tornadic storms, and until hail cessation (via HCA data) for non-tornadic storms.

\section{Analysis}

\section{a. Tornadic storm life cycles}

Analysis of storm track data began by determining if there were any obvious differences between locations of tornado and hail reports in NYS (Fig. 4). An obvious difference does exist in areas of western NYS, where there is a gap of tornadic events running approximately the length of Lake Ontario that coincides with a clustering of severe hail reports (black oval in Fig 4). The differences may indicate that there is something in this region that favors severe convection development and/or persistence, but does not favor tornadogenesis. There also are large numbers of severe reports near Binghamton and Albany, New York, and significant gaps in reports elsewhere, in particular extreme northern NYS. Owing to complex topography, particularly in northern NYS and east-central PA, there are fairly large radar "holes" where either the lowest level sweep of a radar beam is too high to determine a prominent TVS or there is beam blocking because of topography. There is not an obvious correspondence between tornado reports and radar coverage, however, the two aforementioned gaps are found where there is poor low-level radar coverage: half-way between the KBGM and KBUF sites, and between the KTYX and KCXX sites. These radar "holes" may lead to unreported tornadoes owing to a lack of high-resolution radar data at low levels, that otherwise would indicate possible tornado occurrence (via TVS observations on nearby radars) regardless of population density. However, it is most likely that the lack of reports in these two areas are primarily driven by lower population densities (Fig. 1) and poor radar coverage is a secondary factor.

In comparison, neither radar coverage nor population biases would explain the lack of tornado reports in western NYS along the shores of Lakes Ontario and Erie, nor the apparent increase in reports moving into central and eastern NYS. A kernel density estimate of both hail and tornado reports was completed (not shown) and determined that the highest frequency of tornado occurrence occurs coincident with the Mohawk Valley in Central NYS and extends eastward to where the Hudson and Mohawk valleys meet. The occurrence of hail however is fairly evenly distributed through western and central NYS. As discussed in section 1 , the relatively small number of tornado reports in this region makes generalizing trends more difficult as this spatial distribution could be biased by population gradients or arise from chance, whereas a true signal would take many more years of reports to be significant. As a result, the rest of this study focuses on whether there is evidence from storm life cycle data to support the hypothesis that tornadoes are more likely in central and/or eastern NYS than in western NYS.

Analyzing storm tracks rather than reports allows us to focus on when, relative to CI, a storm became tornadic or produced severe hail. Specifically, if there were no true tornadogenesis "hot spots" within NYS, it would be expected that there would be no relationship between where storms initiated and how long they took to produce severe weather. An examination of the tornadic storm life cycle prior to tornadogenesis was completed for 58 storms by relating the longitude of CI of NYS tornadic storms ${ }^{3}$ (as storms almost always move with an eastward component) to the distances the storms traveled before tornadogenesis occurred (Fig. 5). If a storm produced more than one tornado during its lifetime, only the first tornado it produced was considered. This examination also includes storms that initiated in NYS but produced a tornado outside of NYS $(\mathrm{N}=12$; denoted by the diamonds in Fig. 5). However, virtually all of this subset of storms initiated in the vicinity of, or east of, the valleys such that they likely were not mature enough to produce tornadoes regardless of their ingestion of favorable terrain-influenced air. Each of the storms is categorized by convective mode at time of tornadogenesis by way of colored data points where red is a supercell, blue is a QLCS, and green is a nonsupercell (including multi-cell clusters). The resulting

\footnotetext{
${ }^{3}$ Many of the storms responsible for NYS tornadoes initiated in Pennsylvania, and two each initiated in West Virginia, Ohio, and Canada.
} 


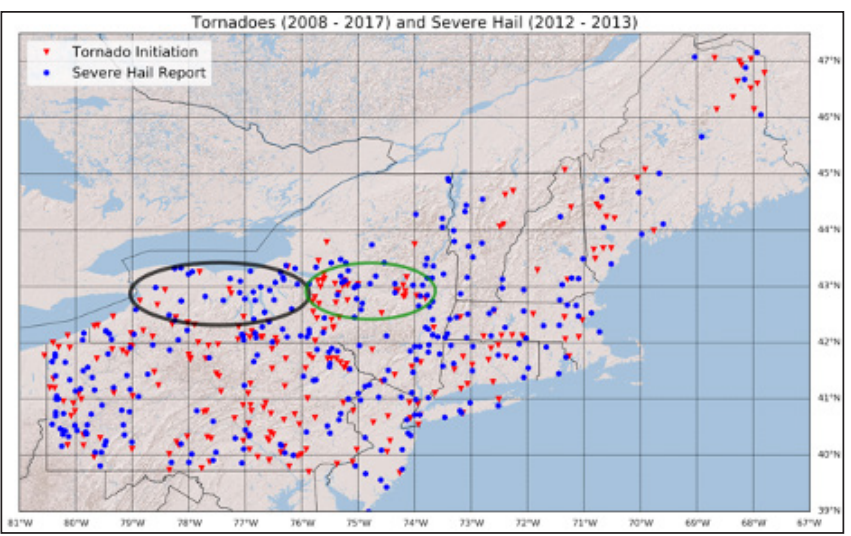

Figure 4. Severe hail reports from 2012 to 2013 and tornado reports from 2008 to 2017 in the NEUS. Black oval indicates western NYS. Green oval indicates Mohawk Valley region of NYS.

strong negative linear correlation coefficient $(\mathrm{CC}=$ -0.67) is consistent with a tendency for the "spin-up" time for tornadogenesis to decrease as storms initiate closer to the valley regions in NYS. The relationship is similar for supercells $(\mathrm{CC}=-0.82)$ and QLCSs (CC $=-0.77)$, but weaker for non-supercells $(\mathrm{CC}=-0.58)$. Table 1 summarizes cases of tornadic and non-tornadic cells by convective mode. These results are additional circumstantial evidence that the terrain in central and eastern NYS provides local mesoscale enhancement of the NSE and ultimately results in a shorter spin-up time for tornadogenesis relative to areas where this low-level environmental enhancement is lacking (e.g., western NYS and Pennsylvania).

One possible alternative explanation for "delayed" tornadogenesis in western NYS and Pennsylvania storms is the diurnal cycle of convection, in that storms are most likely in the NEUS from 1800 to 0000 UTC (Murray and Colle 2011). Data were split between "early" (1200 to 1800 UTC) and "late" (1800 to 1200 UTC) CI, and found to not have a large impact in the correlation between the longitude of CI of a tornadic cell and the distance it traveled before becoming tornadic (not shown). Other potential causes of delayed tornadogenesis in western NYS storms outside of terrain effects, like synoptic scale environments (e.g., warm fronts, low-level troughs), are not investigated in this study. We view such larger-scale conditions as more important for storm CI, convective mode, and establishing background conditions that mesoscale effects can enhance. Nonetheless, the large number of cases analyzed and the strong CC suggests the delayed tornadogenesis signal is one that is not relegated to

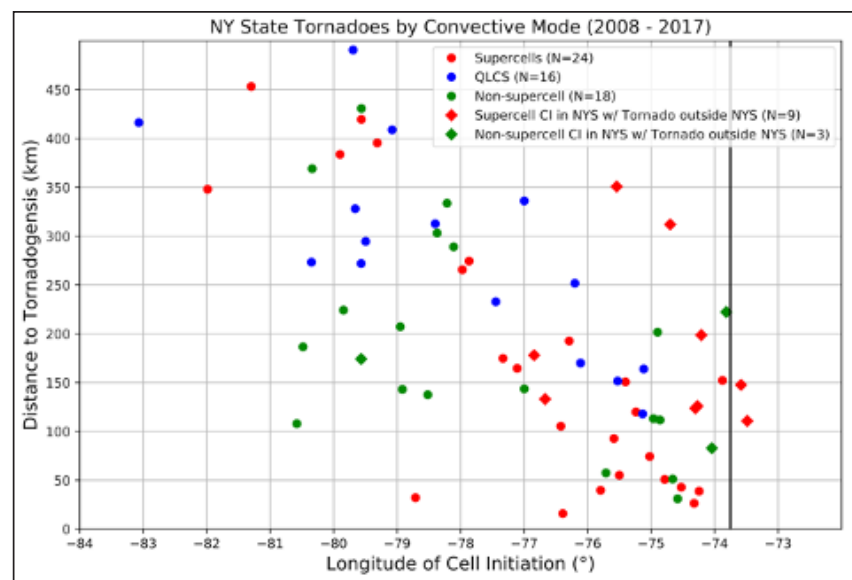

Figure 5. Scatterplot of NYS tornadoes (2008 to 2017) showing the relationship between the longitude of CI $\left(^{\circ}\right)$ of the associated storm cells and the distance traveled $(\mathrm{km})$ by the cells before tornadogenesis. The black line roughly indicates the approximate longitude of the Hudson Valley. ( $\mathrm{N}=70 ; \mathrm{CC}=-0.67$ ) Diamonds indicate storms that initiated in NYS but produced a tornado outside of NYS. Red points indicate a tornado formed from a supercell $(\mathrm{CC}=-0.82)$. Blue points indicate a tornado formed from a QLCS $(\mathrm{CC}=-0.77)$. Green points indicate a tornado formed by neither supercells nor QLCSs (includes multi-cells without midlevel rotation; $\mathrm{CC}=-0.58$ ).

just one type of synoptic-scale flow. Also, a similar relationship between storm CI and hail production does not exist (not shown), consistent with results discussed earlier in section 3a. Therefore, we believe the relationship shown in Fig. 5 is consistent with prior case-study-based research of the potential mesoscale local enhancement of the NSE surrounding the Mohawk and Hudson valleys.

\section{b. Storm environments}

To further investigate the potential impacts of the local topography and nearby Great Lakes in western and central NYS on storm behavior, an analysis of the NSE for a subset of tornadic and non-tornadic cases was completed. The subset of tornadic cases analyzed in the environmental portion of this study are those that have produced a tornado in the vicinity of the Mohawk Valley in central New York but also have traversed over or near western NYS. The approximate straightline tracks of this subset of tornadic storms from CI to tornadogenesis are shown in Fig. 6. These specific cases were used to investigate whether there are trends 
Table 1. Tornadic (2008 to 2017), non-tornadic (2015 to 2017), and combined severe storms in NYS organized by convective mode.

\begin{tabular}{|c|c|c|c|}
\hline Convective Mode & Tornado & Hail $>\mathbf{2 . 5} \mathbf{~ c m ~ ( > 1 ~ i n ) ~}$ & Combined \\
\hline Supercells & 24 & 46 & 70 \\
\hline QLCS & 16 & 0 & 16 \\
\hline Non-supercells & 18 & 38 & 56 \\
\hline Total & 58 & 84 & 142 \\
\hline
\end{tabular}

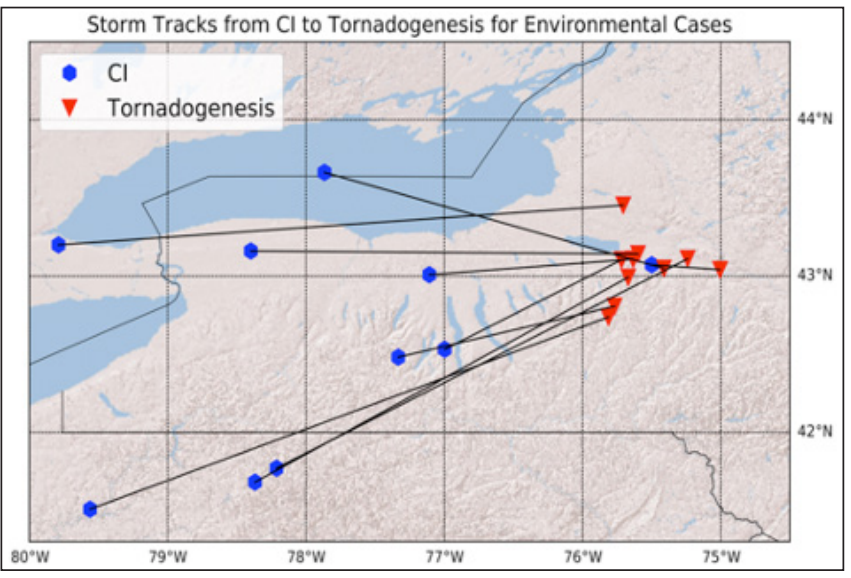

Figure 6. Approximate straight-line storm tracks from CI to tornadogenesis for the subset of tornadic cases analyzed for NSE variables $(\mathrm{N}=10)$.

in the NSE variables as cells move from western NYS or Pennsylvania to central NYS in the vicinity of the Mohawk Valley. The subset of tornadic cases each contain at least four data points (a single case had only three data points) of the hourly 13-km RAP analysis so trends in each NSE variable could be identified leading up to tornadogenesis for each case.

A non-tornadic subset of cases also was marked for environmental analysis to better determine if NSE changes observed in tornadic cases are unique to tornado formation. Non-tornadic cases were chosen based on the time it took for cells to produce an observed severe hail report. As severe hail often occurs relatively early in the storm life cycle compared to tornadogenesis, the non-tornadic cases tended to have fewer data points available for examining NSEs at hourly intervals. To increase the number of NSE data points for non-tornadic cases, the length of time the NSE was analyzed over was based on when the HCA ceased identifying hail for each case as opposed to the time it took for a storm to become severe after CI. In addition, to make a fair comparison with the tornadic set, cases were excluded from this analysis if they initially traversed an area that is not in the vicinity of western NYS or Pennsylvania.
The number of non-tornadic cases that ultimately were selected for environmental analysis is similar to the tornadic subset to maintain consistency in sample sizes $(\mathrm{N}=15)$.

Previous work from Katona et al. (2016) implies that mesoscale effects important for establishing favorable tornadic environments are related to the direction of the low-level flow. Therefore, each of the tornadic and non-tornadic cases were separated into southeasterly (SE) and southwesterly (SW) lowlevel flow regimes based on the direction of the 10-m wind determined using the regional wind field ahead of the cell of interest just before tornadogenesis or just before the first severe hail report. Flow regimes were categorized identically to Katona et al. (2016), where regional (i.e., not just immediately downstream of the storm) $10 \mathrm{~m}$ wind directions $<210^{\circ}$ are considered SEflow events and $>210^{\circ}$ are considered SW-flow events based on the approximate angle of the Appalachian Mountains. Owing to the small sample of storm environments analyzed, trends rather than specific values of environmental variables are emphasized.

\section{1) Tornadic environments}

As discussed previously, the variables analyzed include SBCAPE, 0-1 km SRH, 2-m RH, and DD, and are all associated with conditions important to tornado formation. The evolution of these parameters leading up to tornado formation is shown in Fig. 7 and summarized in Table 2. For tornadic cases, the difference between flow regimes is evident; out of the 10 cases analyzed, eight occurred in the SE-flow regime and only two occurred in the SW-flow regime. The SE-flow regime had previously been identified to have enhanced 0-1 $\mathrm{km}$ SRH over central NYS by Katona et al. (2016). The SW-flow regime averages are shown for completeness, but the sample size is far too low to glean any trends.

SBCAPE values are not high for the tornadic storms: moderately unstable values in most cases (200 to $1000 \mathrm{~J} \mathrm{~kg}^{-1}$ ) (Fig. 7a). When averaging over all cases, 
Table 2. Values of each NSE variable for tornadic cases at CI (top) and tornadogenesis (bottom).

\begin{tabular}{|c|c|c|c|c|}
\hline \multicolumn{5}{|c|}{ CI Environmental Values for Tornadic Cases } \\
\hline $\begin{array}{l}\text { Wind Flow } \\
\text { Regime }\end{array}$ & $\begin{array}{l}\text { SBCAPE } \\
\left(\mathrm{J}^{\left.-\mathrm{kg}^{-1}\right)}\right.\end{array}$ & $\begin{array}{c}\text { 0-1 km SRH } \\
\left(\mathrm{m}^{2} \mathrm{~s}^{-2}\right)\end{array}$ & $\begin{array}{l}\text { Relative Humidity } \\
\text { (\%) }\end{array}$ & $\begin{array}{c}\text { Dewpoint } \\
\text { Depression }\left({ }^{\circ} \mathrm{C}\right)\end{array}$ \\
\hline SE & 800 & 100 & 58 & 5 \\
\hline $\mathrm{SE}$ & 250 & 220 & 72 & 3 \\
\hline SE & 800 & 130 & 90 & 1 \\
\hline $\mathrm{SE}$ & 900 & 120 & 60 & 4.5 \\
\hline SE & 800 & 100 & 65 & 4 \\
\hline SE & 1100 & 80 & 52 & 6 \\
\hline $\mathrm{SE}$ & 860 & 60 & 60 & 5 \\
\hline SE & 350 & 70 & 75 & 3 \\
\hline SW & 125 & 200 & 70 & 3 \\
\hline SW & 400 & 60 & 75 & 3 \\
\hline
\end{tabular}

\begin{tabular}{|c|c|c|c|c|}
\hline \multicolumn{5}{|c|}{ Tornadogenesis Environmental Values for Tornadic Cases } \\
\hline $\begin{array}{l}\text { Wind Flow } \\
\text { Regime }\end{array}$ & $\begin{array}{c}\text { SBCAPE } \\
\left(\mathrm{J}^{\left.-\mathrm{kg}^{-1}\right)}\right.\end{array}$ & $\begin{array}{c}0-1 \mathrm{~km} \text { SRH } \\
\left(\mathrm{m}^{2} \mathrm{~s}^{-2}\right)\end{array}$ & $\begin{array}{c}\text { Relative Humidity } \\
(\%)\end{array}$ & $\begin{array}{c}\text { Dewpoint } \\
\text { Depression }\left({ }^{\circ} \mathrm{C}\right)\end{array}$ \\
\hline SE & 1200 & 150 & 75 & 3 \\
\hline SE & 300 & 300 & 70 & 2 \\
\hline SE & 800 & 180 & 90 & 1 \\
\hline $\mathrm{SE}$ & 700 & 200 & 80 & 1.5 \\
\hline $\mathrm{SE}$ & 1000 & 210 & 75 & 3 \\
\hline SE & 1100 & 160 & 70 & 3.5 \\
\hline $\mathrm{SE}$ & 820 & 220 & 80 & 2 \\
\hline SE & 1000 & 250 & 60 & 4.5 \\
\hline SW & 200 & 150 & 90 & 1 \\
\hline SW & 750 & 100 & 75 & 3 \\
\hline
\end{tabular}

SBCAPE generally increases a small amount leading up to tornado formation. Generally, the environment among tornadic cases indicates that moderate amounts of CAPE are adequate for severe weather in the presence of sufficient amounts of other favorable environmental parameters (e.g., Lombardo and Colle 2011; Hurlbut and Cohen 2014).

Figure $7 \mathrm{~b}$ shows trends in $0-1 \mathrm{~km} \mathrm{SRH}$, where values of at least $100 \mathrm{~m}^{2} \mathrm{~s}^{-2}$ have been shown to be more supportive of tornadic supercells than lesser values. As can be seen by the green line, the average low-level SRH increases steadily prior to tornadogenesis, likely owing to storms moving away from the marine-influenced air mass (i.e., more stable with a less favorable lowlevel wind direction) in western NYS and/or toward the terrain-enhanced areas in central NYS. In addition, the SE-flow regime cases all largely experienced increasing
0-1 km SRH, whereas the only case that saw a reduction in $0-1 \mathrm{~km}$ SRH occurred in SW flow.

The evolution of 2-m RH and the DD, respectively, prior to tornadogenesis, also are shown (Fig. 7c, d). A moister atmosphere and a lower DD at the surface infer lower LCLs and are associated with a higher likelihood of tornadogenesis (Rasmussen and Blanchard 1998). The RH of storms tends to increase slightly in the hours prior to tornadogenesis (Fig. 7c); similarly, the DD decreases steadily prior to tornadogenesis in most cases (Fig. 7d). Physical reasoning for the increase in $\mathrm{RH}$ and decrease in DD may involve ambient temperature cooling from anvil shading or moisture channeling and convergence in proximity to the Mohawk Valley. Flow regime differences are subtle, but SE flow tends to provide the best overall environment to produce tornadoes. 


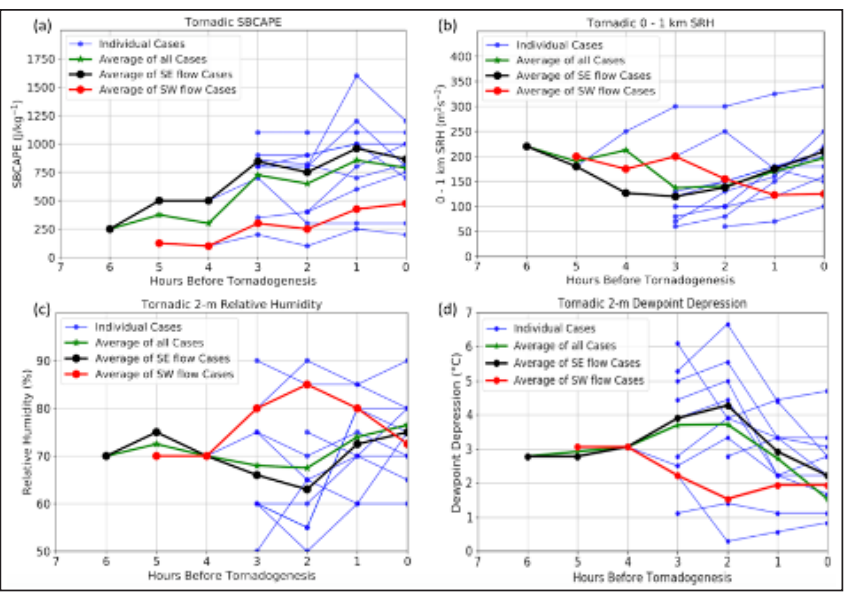

Figure 7. Backward hourly time steps of: (a) SBCAPE (J kg-1); (b) 0-1 km SRH $\left(\mathrm{m}^{2} \mathrm{~s}^{-2}\right)$; (c) $2 \mathrm{~m}$ relative humidity (\%); and (d) surface dewpoint depression $\left({ }^{\circ} \mathrm{C}\right)$ for the subset of tornadic cases $(\mathrm{N}=10)$ from $\mathrm{CI}$ to tornadogenesis. Hour 0 is the last point analyzed before tornadogenesis. Blue lines indicate individual cases. The green line indicates the average for all cases. The black line indicates the average of all SE-flow cases ( $\mathrm{N}$ $=8$ ). The red line indicates the average of all SW-flow cases $(\mathrm{N}=2)$.

\section{2) Non-tornadic environments}

Non-tornadic cases were analyzed in a similar way to tornadic cases, but the shorter duration between $\mathrm{CI}$ and severe hail reports necessitated that hourly environmental analysis occurred from CI to the final hail-identifying HCA scan for each case. Figure 8 shows data from the time steps prior to the easternmost point where the cells severe life cycle ended. The severe hail report for each case could have happened at any hour in this time step analysis, where hour 0 is the easternmost point made by the cell. If the cell remained severe beyond NYS, hour 0 is the location closest to $-74.0^{\circ}$ longitude, or the approximate longitude of the Hudson Valley in eastern NYS. In terms of flow regimes, out of 15 total non-tornadic cases, five occurred in the SEflow regime and 10 occurred in the SW-flow regime. The environmental data are summarized in Table 3.

Non-tornadic events occurred in a significantly higher SBCAPE environment than that of tornadic events (Fig. 8a). The higher SBCAPE values are likely related to the use of severe hail reports to identify the non-tornadic set of cases. SBCAPE values of analyzed cases tend not to change much over the duration of cell life cycles. A subtle decrease in values of SBCAPE toward the easternmost point (hour 0 ) is likely because environments were analyzed until the last hailidentifying HCA scan, when cells would generally have been weakening already.

As hypothesized, 0-1 km SRH for non-tornadic cases (Fig. 8b) is significantly less than that of tornadic cases (Fig. 7b). Environments consistently had $<100 \mathrm{~m}^{2}$ $\mathrm{s}^{-2}$ of $0-1 \mathrm{~km}$ SRH and exhibited only small changes during the times they were likely producing severe hail. Also, the differences between flow regimes are minimal. The low $0-1 \mathrm{~km}$ SRH values are likely one reason why these storms did not produce tornadoes as these storm modes were less likely to include supercells. The 2-m RH values are evidence of a drier boundary layer (BL) in non-tornadic cases than in tornadic cases (Figs. 7c, 8c). For the non-tornadic cases, the SE-flow regime maintains a moister BL than the SW-flow cases. DDs tend to decrease as the cells move into central and eastern NYS, but still maintain a significantly drier environmental state than in tornadic cases (Fig. $8 d)$. These results are consistent with a scenario where valley effects still locally enhanced conditions more supportive of tornadoes, but background synopticscale environmental conditions were less supportive for tornadoes as a whole.

\section{Summary and conclusions}

The primary result from this study is the apparent delayed onset of tornadogenesis in storms initiating in western NYS and Pennsylvania, and the subsequent hastening of tornadogenesis in central and eastern NYS storms. This result is consistent with the hypothesis that storms encounter a more favorable environment in central and eastern NYS than in areas that are influenced by nearby stabilized marine air (western NYS). The results were determined by manually tracking both tornadic and non-tornadic cells in NYS (via radar) and examining their life cycle characteristics. The relationship between the longitude of tornadic storm CI and the distance these tornadic cells traveled from CI to tornadogenesis is evidence that storms that encounter the more complex terrain in NYS are more likely to be tornadic. The hypothesized physical reasoning for this result is the enhancement of low-level wind shear and moisture flux via channeled low-level flow in the Mohawk and/or Hudson valleys.

To test the physical reasoning for delayed tornadogenesis in NYS, storm environments in a subset of cases were examined. Although the sample size is small, at least one favorable tornadic environmental 
Table 3. Values of each NSE variable for non-tornadic cases at CI (top) and at easternmost point (bottom).

\begin{tabular}{|c|c|c|c|c|}
\hline \multicolumn{5}{|c|}{ CI Environmental Values for Tornadic Cases } \\
\hline $\begin{array}{l}\text { Wind Flow } \\
\text { Regime }\end{array}$ & 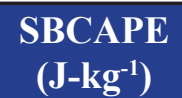 & $\begin{array}{c}\text { 0-1 km SRH } \\
\left(\mathrm{m}^{2} \mathrm{~s}^{-2}\right)\end{array}$ & $\begin{array}{c}\text { Relative Humidity } \\
(\%)\end{array}$ & $\begin{array}{c}\text { Dewpoint } \\
\text { Depression }\left({ }^{\circ} \mathrm{C}\right)\end{array}$ \\
\hline SE & 1250 & 75 & 60 & 5 \\
\hline SE & 1300 & 35 & 60 & 4.5 \\
\hline SE & 1000 & 70 & 70 & 3.5 \\
\hline SE & 750 & 200 & 80 & 2 \\
\hline SE & 1100 & 30 & 80 & 1 \\
\hline SW & 750 & 150 & 58 & 5 \\
\hline SW & 2000 & 10 & 65 & 5 \\
\hline SW & 1300 & 30 & 60 & 4.5 \\
\hline SW & 900 & 30 & 75 & 3 \\
\hline SW & 1150 & 175 & 60 & 4.5 \\
\hline SW & 1200 & 40 & 75 & 3 \\
\hline SW & 900 & 30 & 65 & 4 \\
\hline SW & 900 & 40 & 60 & 4 \\
\hline SW & 1300 & 75 & 80 & 2 \\
\hline SW & 1300 & 50 & 85 & 1.5 \\
\hline
\end{tabular}

\begin{tabular}{|c|c|c|c|c|}
\hline \multicolumn{5}{|c|}{ Easternmost Environmental Values for Non-tornadic Cases } \\
\hline $\begin{array}{l}\text { Wind Flow } \\
\text { Regime }\end{array}$ & $\begin{array}{c}\text { SBCAPE } \\
\left(\mathrm{J}^{\left.-\mathrm{kg}^{-1}\right)}\right.\end{array}$ & $\begin{array}{c}\text { 0-1 km SRH } \\
\left(\mathrm{m}^{2} \mathrm{~s}^{-2}\right)\end{array}$ & $\begin{array}{c}\text { Relative Humidity } \\
(\%)\end{array}$ & $\begin{array}{c}\text { Dewpoint } \\
\text { Depression }\left({ }^{\circ} \mathrm{C}\right)\end{array}$ \\
\hline SE & $500 \mathrm{~J} \mathrm{~kg}^{-1}$ & $130 \mathrm{~m}^{2} \mathrm{~s}^{-2}$ & $85 \%$ & $2{ }^{\circ} \mathrm{C}$ \\
\hline SE & 1500 & 50 & 65 & 4 \\
\hline $\mathrm{SE}$ & 1700 & 60 & 60 & 4.5 \\
\hline SE & 100 & 100 & 85 & 1.5 \\
\hline $\mathrm{SE}$ & 500 & 80 & 90 & 1 \\
\hline SW & 0 & 450 & 70 & 3.5 \\
\hline SW & 2300 & 10 & 70 & 4 \\
\hline SW & 800 & 25 & 70 & 4 \\
\hline SW & 650 & 15 & 70 & 3 \\
\hline SW & 500 & 250 & 55 & 4.5 \\
\hline SW & 850 & 50 & 75 & 2.5 \\
\hline SW & 1000 & 30 & 60 & 4.5 \\
\hline SW & 1000 & 70 & 65 & 4 \\
\hline SW & 1750 & 40 & 75 & 2.5 \\
\hline SW & 1800 & 50 & 80 & 2 \\
\hline
\end{tabular}

condition was enhanced with time for each of the tornadic cases examined (e.g., an increase in $0-1 \mathrm{~km}$ $\mathrm{SRH}$, increase in $\mathrm{RH}$, and/or a decrease in DD) showing that the NSEs trend in a more favorable direction for storms to become tornadic. Non-tornadic cases generally have more SBCAPE, lower $0-1 \mathrm{~km}$ SRH, and a drier BL than tornadic cases, and trends in these conditions as the accompanying storm moved eastward were small, but more favorable for tornadoes. Although sample sizes were small in this environmental aspect of 


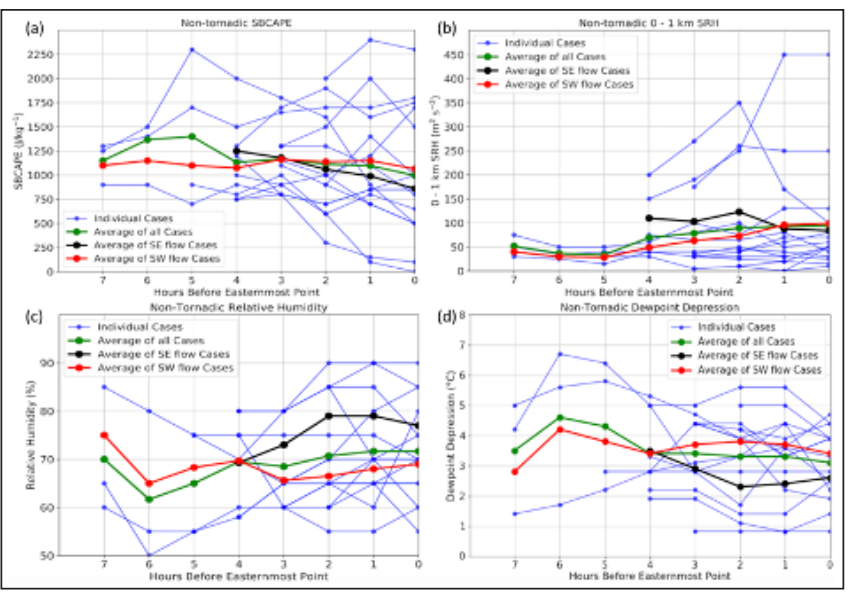

Figure 8. Backward hourly time steps of: a) SBCAPE (J $\left.\mathrm{kg}^{-1}\right)$; b) 0-1 km SRH $\left(\mathrm{m}^{2} \mathrm{~s}^{-2}\right)$; c) 2-m relative humidity $(\%)$; and d) surface dewpoint depression $\left({ }^{\circ} \mathrm{C}\right)$ for the subset of non-tornadic cases $(\mathrm{N}=15)$ from $\mathrm{CI}$ to the easternmost point in NYS. Hour 0 is the easternmost point closest to $-74^{\circ}$ longitude (Hudson Valley). Blue lines indicate individual cases. The green line indicates the average for all cases. The black line indicates the average of all SE-flow cases $(\mathrm{N}=5)$. The red line indicates the average of all $\mathrm{SW}$-flow cases $(\mathrm{N}=10)$.

the study, the differences between severe storm type and flow regime direction are large: a significant majority of tornadic cases $(8 / 10$ or $80 \%)$ occurred in a SE-flow regime and a majority of non-tornadic, severe hail cases occurred in the SW-flow regime (10/15 or $66 \%$ ). As a result, tornadogenesis failure in the non-tornadic cases may have been influenced by, among other possibilities, smaller amounts of low-level wind shear and BL moisture in the synoptic-scale environment and/ or a lack of SE low-level flow that would act to locally enhance these values in the valley regions.

We believe all of the pieces of information shown and discussed herein combined with findings from past studies support the idea that, particularly in SEflow regimes, convective storms enter a more favorable environment to produce tornadoes as they enter the valley regions of NYS. We advise forecasters in this region to use this information while tracking and nowcasting severe weather. Most notably they should be cognizant that even very long-lived convective storms that do not have a history of tornado formation may be more likely to become tornadic in central and eastern NYS, assuming favorable environments. We await a longer accumulation of storm reports, more in-depth case studies, numerical modeling work, and the collection of high-resolution remote sensing and environmental data to better understand the interplay between the valley region terrain and the NSE in NYS. Future work regarding local NSEs in particular offers promise with the installation of the NYS Mesonet (Brotzge et al. 2016), that better samples how nearsurface conditions may become more or less suitable for tornado formation in specialized areas owing to marine and terrain effects. In addition, we see the potential for mobile research-quality radar combined with highresolution satellite data from Geostationary Operational Environmental Satellite (GOES)-16 (Schmitt et al. 2017) and mobile radiosonde observations as another way to investigate in-depth how channeled flow affects the NSE and how changes in the NSE may impact storm evolution, including the tornadogenesis process, over short time scales. Although this analysis is focused on NYS, we encourage the application of this analysis to other regions of the world (e.g., Lyza and Knupp 2018) that have similar difficulties determining if and how local complex terrain and/or marine influences enhance or stifle the NSEs of deep convection.

Acknowledgments: This study was supported by NASA Grant NNX15AQ59G. We thank Pavlos Kollias and Brian Colle for the helpful comments they provided, which enhanced the first author's M.S. thesis at Stony Brook University. Comments from Branden Katona (Penn State University) and two anonymous reviewers greatly enhanced this paper.

\section{REFERENCES}

Bosart, L. F., A. Seimon, K. D. LaPenta, and M. J. Dickinson, 2006: Supercell tornadogenesis over complex terrain: The Great Barrington, Massachusetts, tornado on 29 May 1995. Wea. Forecasting, 21, 897-922. CrossRef.

Brooks, H. E., C. A. Doswell III, and M. P. Kay, 2003: Climatological estimates of local daily tornado probability for the United States. Wea. Forecasting, 18, 626-640. CrossRef.

Brotzge, J.A., C. Thorncroft, and E. Joseph, 2016: The New York State Mesonet: a technical overview. 22nd Conf. on Applied Climatology, New Orleans, LA, Amer. Meteor. Soc., P3.5. Available online at ams.confex.com/ ams/96Annual/webprogram/Paper283586.html.

Brown, R. A., L. R. Lemon, and D. W. Burgess, 1978: Tornado detection by pulsed Doppler radar. Mon. Wea. Rev., 106, 29-38. CrossRef. 
Colle, B. A., K. A. Lombardo, J. S. Tongue, W. Goodman, and N. Vaz, 2012: Tornadoes in the New York metropolitan region: climatology and multiscale analysis of two events. Wea. Forecasting, 27, 1326-1348. CrossRef.

French, M. M., H. B. Bluestein, L. J. Wicker, D. C. Dowell, and M. R. Kramar, 2009: An example of the use of mobile, Doppler radar data for tornado verification. Wea. Forecasting, 24, 884-891. CrossRef.

Fujita, T. T., 1989: The Teton-Yellowstone tornado of 21 July 1987. Mon. Wea. Rev., 117, 1913-1940. CrossRef.

Hurlbut, M. M., and A. E. Cohen, 2014: Environments of northeast U.S. severe thunderstorm events from 1999 to 2009. Wea. Forecasting, 29, 3-22. CrossRef.

Johns, R. H., and R. A. Dorr, 1996: Some meteorological aspects of strong and violent tornado episodes in New England and eastern New York. Nat. Wea. Dig., 20, 2-12. [Available online at nwafiles.nwas.org/digest/ papers/1996/Vol20No4/Pg2-Johns.pdf].

Katona, B., P. Markowski, C. Alexander, and S. Benjamin, 2016: The influence of topography on convective storm environments in the eastern United States as deduced from the HRRR. Wea Forecasting, 31, 1481-1490. CrossRef.

Knupp, K. R., and Coauthors, 2014: Meteorological overview of the devastating 27 April 2011 Tornado Outbreak. Bull. Amer. Meteor. Soc., 95, 1041-1062. CrossRef.

Kovacs, M. and D. J. Kirshbaum, 2016: Topographic impacts on the spatial distribution of deep convection over southern Quebec. J. Appl. Meteor., 55, 743-762. CrossRef.

Kuster, M. C., P. Burke, and A. A. Taylor, 2012: An 11-year radar-based study of tornadic thunderstorms over central Oklahoma. Electronic J. Severe Storms Meteor., 7 (8), 1-18. [Available online at www.ejssm.org/ojs/index. php/ejssm/article/view/103/86].

LaPenta, K. D., L. F. Bosart, T. J. Galarneau Jr., and M. J. Dickinson, 2005: A multiscale examination of the 31 May 1998 Mechanicville, New York, tornado. Wea. Forecasting, 20, 494- 516. CrossRef.

Lombardo, K. A., and B. A. Colle, 2010: The spatial and temporal distribution of organized convective structures over the Northeast and their ambient conditions. Mon. Wea. Rev., 138, 4456-4474. CrossRef. , and _ 2011: Convective storm structures and ambient conditions associated with severe weather over the northeast United States. Wea. Forecasting, 26, 940956. CrossRef. , and _ 2012: Ambient conditions associated with the maintenance and decay of quasi-linear convective systems crossing the northeastern U.S. coast. Mon. Wea. Rev., 140, 3805-3819. CrossRef.
, and ,2013: Processes controlling the structure and longevity of two quasi-linear convective systems crossing the southern New England coast. Mon. Wea. Rev., 141, 3710-3734. CrossRef.

and T. Kading, 2018: The behavior of squall lines in horizontally heterogeneous coastal environments. $J$. Atmos. Sci., 75, 1243-1269. CrossRef.

Lyza, A. W. and K. R. Knupp, 2018: A background investigation of tornado activity across the southern Cumberland Plateau terrain system of northeastern Alabama. Mon. Wea. Rev., 146, 4261-4278. CrossRef.

Murray, J. C., and B. A. Colle, 2011: The spatial and temporal variability of convective storms over the northeast United States during the warm season. Mon. Wea. Rev., 139, 992-1012. CrossRef.

Park, H. S., A. V. Ryzhkov, D. S. Zrnić, and K. Kim, 2009: The Hydrometeor Classification Algorithm for the polarimetric WSR-88D: Description and application to an MCS. Wea. Forecasting, 24, 730-748. CrossRef.

Rasmussen, E. N., and D. O. Blanchard, 1998: A baseline climatology of sounding-derived supercell and tornado forecast parameters. Wea. Forecasting, 13, 1148-1164. CrossRef.

Roberts, R. D., and S. Rutledge, 2003: Nowcasting storm initiation and growth using GOES-8 and WSR-88D data. Wea. Forecasting, 18, 562-584. CrossRef.

Schaefer, J. T., and J. G. Galway, 1982: Population biases in the tornado climatology. Preprints, 12th Conf. on Severe Local Storms, San Antonio, TX, Amer. Meteor. Soc., 51-54.

Schmitt, T. J., P. Griffith, M. M. Gunshor, J. M. Daniels, S. J. Goodman, and W. J. Lebair, 2017: A closer look at the ABI on the GOES-R series. Bull. Amer. Meteor. Soc., 98, 681-698. CrossRef.

Smith, S. D., R. Oye, and W. C. Lee, 1995: Solo: Window based software for perusing and editing radar data. Ninth Symposium on Meteorological Observations and Instrumentation, Charlotte, NC. Amer. Meteor. Soc., 279-281.

Tang, B., M. Vaughn, R. Lazear, K. Corbosiero, L. Bosart, T. Wasula, I. Lee, and K. Lipton, 2016: Topographic and boundary influences on the 22 May 2014 Duanesburg, New York, tornadic supercell. Wea. Forecasting, 31, 107-127. CrossRef.

Thompson, R. L., R. Edwards, J. A. Hart, K. L. Elmore, and P. Markowski, 2003: Close proximity soundings within supercell environments obtained from the Rapid Update Cycle. Wea. Forecasting, 18, 1243-1261. CrossRef. 
Torres, S., and C. Curtis, 2007: Initial implementation of super-resolution data on the NEXRAD network. $23 \mathrm{rd}$ Int. Conf. on Interactive Information and Processing Systems for Meteorology, Oceanography, and Hydrology, San Antonio, TX, Amer. Meteor. Soc., 5B.10. [Available online at pdfs.semanticscholar. org/784c/0503bf8b6bc75894b697fb4debd070f69248. pdf? ga=2.77635412.1955930035.15897659421374070293.1589765942]

Trapp, R. J., E. D. Mitchell, G. A. Tipton, D. W. Effertz, A. I. Watson, D. L. Andra Jr., and M. A. Magsig, 1999: Descending and nondescending tornadic vortex signatures detected by WSR-88Ds. Wea. Forecasting, 14, 625-639. CrossRef.

Wasula, A. C., L. F. Bosart, and K. D. LaPenta, 2002: The influence of terrain on the severe weather distribution across interior eastern New York and western New England. Wea. Forecasting, 17, 1277-1289. CrossRef.

Witt, A., M. D. Eilts, G. J. Stumpf, E. D. Mitchell, J. T. Johnson, and K. W. Thomas, 1998: Evaluating the performance of WSR-88D severe storm detection algorithms. Wea. Forecasting, 13, 513-518. CrossRef.

Wurman, J. M., C. Alexander, P. Robinson, and Y. P. Richardson, 2007: Low-level winds in tornadoes and potential catastrophic tornado impacts in urban areas. Bull. Amer. Meteor. Soc., 88, 31-46. CrossRef. 